with severe respiratory syncytial virus infection. Crit Care Med 1987;15:1051-4.

13 Gelfand EW, McCurdy D, Pandu Rao C, Middleton PJ. Ribavirin treatment of viral pneumonitis in severe combined immunodeficiency disease. Lancet 1983;ii:732-3.

14 McIntosh K, Kurachek SC, Cairns LM, Burns JC, Goodspeed B. Treatment of respiratory viral infection in an immunodeficient infant with ribavirin aerosol. Am J Dis Child 1984;138: 305-8.

15 McMillan JA, Tristram DA, Weiner LB, et al. Prediction of the duration of hospitalization in patients with respiratory syncytial virus infection: use of clinical parameters. Pediatrics 1988;81: 22-6.

16 Wyde PR, Wilson SZ, Petrella R, Gilbert BE. Efficacy of highdose-short duration ribavirin aerosol treatment of respiratory syncytial virus infected cotton rats and influenza B virus infected mice. Antiviral Res 1987;7:211-20.

17 Isaacs D. Ribavirin. Pediatrics 1987;79:289-91.

\section{Randomised trials and ribavirin}

'Uncertainty' about whether to use a treatment is the basis of all randomised controlled trials. Indeed, it can be argued that it is unethical not to randomise when there is uncertainty because this ensures that only $50 \%$ of current patients will receive whichever turns out to be the worse management, quite apart from the benefits which accrue to those who have the illness in the future.

Should paediatricians be uncertain whether or not to use ribavirin? The articles on the previous pages certainly suggest that there are widely varying beliefs about the place of this new drug in everyday practice, and variations in practice are a measure of 'collective' uncertainty. Individually, paediatricians should decide by critically appraising the evidence which is 'in the public domain' for themselves. (There are understandable commercial and other reasons why a company may choose not to publish data about a new product, but Dr Snell must recognise that these data cannot then be used as 'public' support for the product). Most weight should be given to the randomised controlled trials. The weakness of using historical controls is illustrated by the apparent change over time in the risk of death due to respiratory syncytial virus in infants with congenital heart disease treated conservatively. Comparisons using concurrent but non-randomised controls are also highly prone to bias. The five properly reported randomised controlled trials included only 76 children treated with ribavirin. They are 'efficacy' or 'explanatory' (can it work?) trials. That is to say, small numbers of patients were investigated in a tightly controlled environment and outcome was assessed by short term surrogate measures such as illness severity scores and arterial oxygen concentrations. These trials do suggest a benefit in these respects, but the clinical significance of this is unclear, particularly in the longer term. Dr Isaacs and his colleagues ( $p$ 986) call for a much larger 'effectiveness' or 'pragmatic' (does it work?) trial to assess ribavirin in everyday practice in terms of clinically more meaningful outcomes such as length of time on a ventilator and length of stay in hospital. Improvement in these terms could offset the high financial cost of treatment.

The possibility of unanticipated adverse effects of ribavirin must also be included in the appraisal. It is reassuring that licensing authorities in the United Kingdom and the United States have given ribavirin a (limited) licence, because these authorities are primarily concerned with drug safety. Nevertheless, the Committee on Safety of Medicines has made special reporting a requirement for ribavirin and the marketing data sheet does mention the possibility of serious side effects in the short term. Furthermore, larger numbers of children must be followed up for much longer before rare, but serious, long term adverse effects can be ruled out with any confidence.

On the basis of the limited evidence currently available paediatricians are likely to come to differing conclusions about the effectiveness and safety of ribavirin. Some may feel that ribavirin must be used in some clinical situations; others may conclude that on present evidence, it has no place in everyday practice. But I suspect that many will be uncertain whether they should use ribavirin for respiratory syncytial virus infection, even for children who are most severely affected or most at risk. If so, this uncertainty can only be resolved by large 'pragmatic' randomised controlled trials as called for by Dr Isaacs and his colleagues.

$$
\begin{array}{r}
\text { Addian Grant } \\
\text { EPIDEMIOLOGIST } \\
\text { National Perinatal Epidemiology Unit, } \\
\text { Radcliffe Infirmary, } \\
\text { Oxford OX2 } 6 H E .
\end{array}
$$

\section{Response}

Dr Snell reaches different figures from us on the number of children who have received ribavirin in controlled trials because of our different interpretation of what constitutes a quotable controlled trial. But this is quibbling: our point was that thousands have been treated on the basis of relatively little controlled data. To use the granting of a product licence by licensing authorities as evidence of efficacy is novel but scientifically unacceptable.

We do not believe that Dr Snell has refuted our three main points, namely that there is no evidence 
for ribavirin decreasing the need for artificial ventilation, reducing hospital stay, or reducing mortality. In attempting to refute the first two points, he quotes a 1985 meeting abstract never published as a paper and 'unpublished data'.

Dr Snell's argument that it would be unethical to test the hypothesis that ribavirin saves lives because babies would die in the trial is an old one and has been used in the United States. ${ }^{1}$ It presupposes that ribavirin does save lives. If this is the case, then a trial will prove to all doubting paediatricians, including the authors of this letter, that the drug should be used for 'at risk' patients. But ribavirin may conceivably increase mortality by aggravating bronchoconstriction or by precipitating in ventilator tubing. A significant reduction in the need for artificial ventilation in 'at risk' infants would, however, be an important finding which might justify early use of ribavirin in such infants. Until this evidence is available, however, we do not consider the routine use of ribavirin in 'at risk' infants to be justified just because ribavirin may be useful. Dr Snell's proposed large scale study on low risk infants does not address these points.

Although one of us previously suggested that ribavirin was indicated in some 'at risk' infants, he also suggested that further controlled trials are needed. ${ }^{2}$ Ribavirin has not been used in Oxford and there have been no deaths from respiratory syncytial virus infection in the last three years although 16 babies have required artificial ventilation. We are alarmed that in the United States ribavirin is widely used even for low risk infants, but would note that Ellen Wald and colleagues at Pittsburgh have recently come to very similar conclusions to $\mathbf{u}^{-}$ regarding the inappropriateness of treating low risk infants with ribavirin, the paucity of controlled data on high risk infants, and the need for large, controlled clinical trials. ${ }^{3}$

\section{References}

1 Conrad DA, Christenson JC, Warner JL, Marks MI. Aerosolized ribavirin treatment of respiratory syncytial virus infection in infants hospitalised during an epidemic. Pediatr Infect Dis J 1987;6:152-8.

2 Isaacs D. Ribavirin. Pediatrics 1987;79:289-91.

${ }^{3}$ Wald ER, Dashefsky B, Green M. In re ribavirin: a case of premature adjudication? $J \cdot$ Pediatr 1988;112:154-8.

D IsaAcs, E R Moxon, D Harvey, I Kovar, C R Madeley, R J Richardson, M Levin, A Whitelaw, and N Modi 